\title{
Proteção Social à Pessoa com Deficiência no Brasil Pós-Constituinte / Social
}

\section{Protection to Person with Disabilities in Brazil after Constituent}

LuCiana Patrícia ZuCCO ${ }^{1}$

Inicio meus comentários registrando a satisfação em debater o presente texto: "Proteção Social à Pessoa com Deficiência no Brasil Pós Constituinte: elementos para debate". Este me suscitou um conjunto de reflexões a medida em que Senna, Lobato e Andrade foram demonstrando a complexa relação que compreende a temática deficiência e assistência social. Tal densidade decorre das dimensões conceituais e estruturais, imbricadas pelos múltiplos aspectos (históricos, culturais, jurídicos, macroeconômicos, entre outros), igualmente abordados pelas autoras ao desenvolverem a discussão.

Ademais, registro os cumprimentos aos responsáveis por este Número, bem como às autoras pelo recorte e abordagem dada ao artigo, cabendo aqui quatro notas. A primeira refere-se à escassez da produção bibliográfica sobre deficiência e, particularmente, sua relação com a política de assistência social no âmbito do Serviço Social. Esta se manteve reduzida mesmo após a promulgação da Convenção Internacional sobre os Direitos das Pessoas com Deficiência, no Brasil, através do Decreto n. 6.949, de 25 de agosto de 2009. Isso porque tal configuração jurídica sugere a necessidade de avaliações na operacionalização das ações programáticas no âmbito tanto do Plano Nacional dos Direitos da Pessoa com Deficiência, quanto do BPC, devido as significativas alterações conceituais da deficiência.

Assistente Social. Doutora em Ciências da Saúde pelo Instituto Fernandes Figueira/IFF/ FIOCRUZ. Professora Adjunta do Departamento de Serviço Social/CSE/UFSC e do Programa de Pós Graduação em Serviço Social/UFSC. 
Um breve levantamento realizado no mês de maio do corrente ano nas Revistas Serviço Social \& Sociedade e Revista Katálysis, ambas de ampla circulação nacional (impressa e online), utilizando o descritor deficiência, indicou a existência de apenas um artigo, em uma edição da Revista Katálysis. Como Tema Livre, o artigo, de autoria de Silva e Diniz (2012), assim como o de Senna, Lobato e Andrade, trabalhou a relação deficiência/Lei Orgânica da Assistência Social (LOAS), com destaque ao BPC. Entretanto, aquele parte de outro pressuposto, qual seja, a relação de inconstitucionalidade entre mínimo social estabelecido pela LOAS e a sobrevivência como padrão para a prestação do Benefício.

Do exposto, chama a atenção o fato de a relação deficiência e BPC, embora ser tema contemporâneo e de política social pública, ter espaço diminuto como objeto de discussão para os assistentes sociais, sendo estes um dos técnicos, assim como o médico perito, responsáveis por proporcionar o acesso dos usuários ao benefício. Esse dado reafirma a importância do artigo apresentado por Senna, Lobato e Andrade e de seu conteúdo àqueles que trabalham com a assistência social.

A segunda nota trata das mudanças conceituais sobre deficiência e sua repercussão para a proteção social. Senna, Lobato e Andrade descrevem a história do conceito de deficiência para discutir suas implicações no âmbito da assistência social, no caso, do BPC. Para tanto, recuperam a principal narrativa presente na história da explicação da deficiência, de ordem biomédica, demonstram o processo de transição para sua compreensão como marco social, e então a apresentam como resultado da interação entre a matriz biomédica e de direitos humanos. As autoras destacam com isso a complexidade e as múltiplas determinações da atual definição plasmada na Convenção Internacional dos Direitos das Pessoas com Deficiência, e ratificada pelo Estado brasileiro (BRASIL, 2009).

Nesse sentido, elas chamam a atenção para a possibilidade de instituir um novo paradigma no campo dos direitos das pessoas deficientes, uma vez que há a necessidade de adequação do arcabouço 
legal e das políticas sociais públicas do país ao conteúdo normativo da Convenção. Entretanto, ao discorrerem sobre os desdobramentos para o campo da política de assistência social, questionam as alterações jurídicas na LOAS (Lei n. 12.435, de 06 de julho de 2011) e se de fato houve ampliação da proteção social. Discutem o entendimento de deficiência, a noção de irreversibilidade, o conceito de família e a concepção de incapacidade.

As reflexões apresentadas por Senna, Lobato e Andrade me reportaram ao pensamento de Silva e Diniz (2012, p. 263), ao afirmarem que as mudanças terminológicas no campo da deficiência têm consequências significativas para o Brasil, "tanto nas questões de reconhecimento quanto nas questões de redistribuição". Por isso, problematizam quem são as pessoas com deficiência e os critérios de acesso instituídos pelas alterações legais ${ }^{2}$ imputadas pela regulamentação da Convenção.

Segundo as autoras, a atual redação da LOAS desconsidera os sentidos políticos de deficiência, os impedimentos, as barreiras e a participação, que vão redundar na restrição de acesso à proteção social. A deficiência não se restringiria a impedimentos corporais, uma vez que nem todo corpo estaria impossibilitado de ir e vir, de participar e de se manifestar devido a sua condição restrita. "É possível uma pessoa ter impedimentos e não experimentar restrições significativas de participação pelas barreiras existentes à vida social" (SILVA e DINIZ, 2012, p. 264). Assim como um contexto social e econômico desfavorável, com carência de políticas sociais públicas, certamente inviabilizaria um deficiente de seu direito de participação. Somam-se a isso a exclusão pela deficiência, o gênero, a raça e etnia, a estética, a idade e a orientação sexual.

Nessa chave interpretativa, Silva e Diniz (2012) enfatizam o social como elemento central para o processo de avaliação, por parte

$\overline{2}$ Ver Lei N.12.435, de 06 de julho de 2011, e Lei N. 12. 470, de 31 de agosto de 2011. 
dos técnicos, da experiência e do reconhecimento de vivências distintas da deficiência, para superação da exclusão e desigualdades sociais. Além disso, a deficiência e a operacionalização da proteção social, via BPC, seriam trabalhadas no sentido de garantir o direito à vida, tendo como norte a vigência dos direitos humanos, ou seja, a busca da igualdade na diversidade. "A proteção social reclama distribuições e reconhecimentos que sejam justos - portanto, que reconheçam diferentes necessidades." (SILVA \& DINIZ, 2012, p. 268)

Outra nota de destaque no pensamento de Senna, Lobato e Andrade é o que designam como 'materialidade' da assistência social, qual seja, as vulnerabilidades sociais, "mas as vulnerabilidades dos mais vulneráveis, tratadas por um sistema próprio e com baixa vinculação aos outros setores sociais" (p. 10). Com propriedade, sustentam tal argumento e sugerem que, embora haja a construção de um sistema público até então inexistente na trajetória da assistência social no país, este "pode estar reiterando esse lugar [de vulnerabilidade] em vez de alterá-lo" (p. 10). Esse debate, além de me reportar às 'questões de redistribuição' apresentadas por Silva e Diniz (2012), me faz lançar mão do entendimento de vulnerabilidade social utilizado por Oliveira (1995) e do pensamento de Sposati (2011) sobre as políticas sociais públicas na América Latina.

A pessoa com deficiência para acessar o BPC tem que comprovar sua pobreza e deficiência para que lhe seja assegurado um mínimo social. Contudo, o patamar é de padrão de sobrevivência. Silva e Diniz (2012) informados pela Convenção travam um debate sobre padrão adequado de vida e criticam a proteção assegurada pelo Benefício, uma vez que ele asseguraria a "sobrevida" (p. 265).

As reflexões abordam a importância do acesso do deficiente às demais políticas sociais públicas, logo, a intersetorialidade como dimensões de direitos sociais. De acordo com Sposati (2011), um dos desafios do século XXI seria a incorporação nas políticas sociais tradicionais das demandas voltadas às pessoas com deficiência como 
direitos humanos e sociais. Desse modo, impossíveis de serem atingidos com mínimos para garantir necessidades aos cidadãos. "A proteção à pessoa com deficiência implica verdadeiramente reconhecer que as necessidades individuais são diferentes e que a determinação de mínimos não deve ser resultado de um cálculo orçamentário, mas da proteção às necessidades individuais". (SILVA \& DINIZ, 2012, p. 268).

É na perspectiva da equidade no âmbito das políticas sociais que recupero a compreensão de vulnerabilidade, segundo Oliveira (1995). Para o autor, esta seria a impossibilidade momentânea ou prolongada de acesso das pessoas a bens e serviços, caracterizados como direitos sociais. Enfatiza que a vulnerabilidade social não se restringe a uma leitura econômica, envolvendo aspectos culturais, de gênero, de raça e etnia. Desloca, dessa forma, a definição de uma noção de carências sociais, diria de restrições e mínimos, para o terreno dos direitos sociais.

Sposati (2011), por sua vez, parte do pressuposto de que os direitos avançaram significativamente nos termos da Lei, na sua operacionalização, progresso sinalizado igualmente por Senna, Lobato e Andrade ao citarem, por exemplo, a realidade do BPC Escola e BPC Trabalho. De acordo com Sposati (2011), as lutas sociais estiveram, no final do século XX, focadas na superação do autoritarismo e da privatização no interior do Estado, mais do que na universalização e na equidade de direitos humanos e sociais. Dito de outro modo, e sem desconsiderar as tendências internacionais e nacionais de restrições às políticas sociais públicas, não há um lastro histórico na elaboração, implementação e controle social, no caso, da proteção social.

Para a autora, o século XXI tem como grande desafio o "de reposicionar o lugar das políticas sociais no enfrentamento das desigualdades sem se transformar em paliativos à pobreza, gerando atenções de segunda categoria” (SPOSATI, 2011, p. 110). A assistência social em sua origem - voltada a quem dela necessitar - seria um dos espaços de exercício da justiça social, mas sua operacionalização reproduz o vulnerável? O BPC seria uma atenção de segunda categoria? 
Essas são indagações passíveis de respostas, mas que requerem processos investigativos de natureza empírica, ou seja, de avaliação da proteção viabilizada à pessoa com deficiência, como ressalta Senna, Lobato e Andrade.

Como última nota, destaco novamente a importância do texto das autoras e compartilho algumas angústias, revestidas de indagações. Chamo a atenção para as reflexões sobre a materialidade da assistência social, e para o debate que o artigo suscita, impossível de restringi-lo a estas páginas. Este se apresenta caro aos profissionais responsáveis pela viabilização do BPC como direito social e humano. A operacionalização do benefício envolve, portanto, dimensões teóricas, jurídicas, políticas, éticas, programáticas e técnicas, manifestadas nas avaliações dos profissionais, sejam elas social ou médico-pericial.

Logo, a avaliação social é tão importante quanto a do médico perito para a promoção da equidade social, embora no cotidiano essa não seja a prática. A posição individual e coletiva dos profissionais acerca do Benefício não se limita ao acesso dos usuários, mas igualmente ao domínio da temática, à qualificação técnica e à visibilidade dos limites mantidos ou atualizados pelas recentes alterações jurídicas. E, nesse sentido, os questionamentos se fazem presentes: como médicos e assistentes sociais se posicionam diante do atual cenário que envolve o BPC? Quais as ações de qualificação promovidas pelo Ministério do Desenvolvimento Social e Combate à Fome (MDS) e pelo Instituto Nacional de Seguro Social (INSS)? Quem produz (formação profissional) sobre a relação deficiência/ BPC? Como essas temáticas são asseguradas a médicos e a assistentes sociais no processo de formação profissional? Essas são apenas questões que se somam ao profícuo debate!

Submetido em 09 de abril de 2013 e aceito para publicação em 12 de maio de 2013 


\section{Referências}

BRASIL. Lei $N^{0} 12.435$, de 6 de julho de 2011. Altera a Lei $\mathrm{N}^{0}$ 8.742, de 7 de dezembro de 1993, que dispõe sobre a organização da Assistência Social. Disponível em: http:/ /www.planalto.gov.br/ccivil_03/_Ato20112014/2011/Lei/L12435.htm. Acesso em 13 ago. 2013.

BRASIL. Lei $N^{o}$ 12. 470, de 31 de agosto de 2011. Altera os arts. $21 \mathrm{e}$ 24 da Lei No 8.212 e dispõe sobre o Plano de Custeio da Previdência Social. Disponível em: http://www.planalto.gov.br/ccivil_03/_ato20112014/2011/lei/112470.htm. Acesso em 13 ago. 2013.

. Decreto No. 6.949, de 25 de agosto de 2009. Promulga a Convenção Internacional sobre os Direitos das Pessoas com Deficiência e seu Protocolo Facultativo. Disponível em: http://www.planalto.gov.br/ ccivil_03/_ato2007-2010/2009/decreto/d6949.htm. Acesso em 13 ago. 2013.

OLIVEIRA, F. Vulnerabilidade Social e Carência de Direitos. Cadernos ABONG I 1995; 9-19.

SILVA, J.L.P. da; DINIZ, D. Mínimo social e igualdade: deficiência, perícia e benefício assistêncial na LOAS. Revista Katálysis. Florianópolis, V. 15, n. 2, p. 262-269, jul/dez. 2012.

SPOSATI, A. Tendências latino-americanas da política social pública no Séc 21. Revista Katálysis. Florianópolis, V. 14, n. 1, p. 104-115, jan/ jun. 2011. 